\title{
Lidocaine added to a tracheostomy tube cuff reduces tube discomfort
}

Waka Hirota DDS PhD, ${ }^{*}$ Wataru Kobayashi DDS PhD, * Keiichi Igarashi DDS PhD, ${ }^{*}$ Yasuko Yagihashi DDS PhD, ${ }^{*}$ Hiroto Kimura DDS PhD, ${ }^{*}$ James Strupish BSc, $†$ Kazuyoshi Hirota MD $\ddagger$

Purpose: To examine whether lidocaine diffusion across an endotracheal tube cuff affects tracheostomy tube discomfort.

Methods: Two tracheostomy tube cuffs were inflated with $5 \mathrm{ml}$ lidocaine $4 \%$ solution and air at $20 \mathrm{cmH}_{2} \mathrm{O}$, and then placed in $20 \mathrm{ml}$ distilled water at $37^{\circ} \mathrm{C}$. After vigorous stirring, $100 \mu \mathrm{l}$ of this water was then sampled immediately then I, 2, 4, 8, $24 \mathrm{hr}$ later to measure lidocaine concentration by high-performance liquid chromatography. Sixteen patients undergoing tracheostomy following oral cancer resection were randomly assigned to two groups: lidocaine $(n=8)$ and placebo $(n=8)$. A tracheostomy tube cuff was inflated with $5 \mathrm{ml}$ lidocaine $4 \%$ or saline $0.9 \%$ and air to a cuff pressure of $20 \mathrm{cmH}_{2} \mathrm{O}$, in the lidocaine and placebo groups respectively. Tube discomfort was evaluated using a visual analogue scale at 0, 0.5, I, 2 and $4 \mathrm{hr}$ after lidocaine or saline administration. Neither analgesics nor sedatives was given during the evaluation period.

Results: Lidocaine time-dependently diffused across the tracheostomy tube cuff. Thirty and 60 min after cuff inflation lidocaine concentrations in the water bath reached approximately 8 and $17 \mu \mathrm{g} \cdot \mathrm{ml}^{-1}$ representing 160 and $340 \mu \mathrm{g}$ in $20 \mathrm{ml}$ of water, respectively. The VAS decreased from $53.5 \pm 10.6$ to $25.1 \pm 9.8 \mathrm{~mm}(P<0.0 \mathrm{I}) 0.5$ $\mathrm{hr}$ following lidocaine administration which continued until the end of evaluation period. In the placebo group, VAS did not change.

Conclusion: Lidocaine diffusion across the tracheostomy tube cuff reduces tube discomfort.

Objectif : Vérifier si la diffusion de lidocaïne au travers du ballonnet du tube endotrachéal a un effet sur l'inconfort lié à la canule de trachéotomie.

Méthode : Deux ballonnets de canules de trachéotomie ont été gonflés avec une solution contenant $5 \mathrm{ml}$ de lidocaïne à $4 \%$ et de l'air dans $20 \mathrm{cmH}_{2} \mathrm{O}$, et placées ensuite dans $20 \mathrm{ml}$ d'eau distillée à $37^{\circ} \mathrm{C}$. Après avoir vigoureusement agité le mélange, on a immédiatement prélevé I00 $\mu$ de cette eau, puis I, 2, 4, 8, 24 h plus tard, pour mesurer la concentration de lidocaïne par chromatographie à haute performance. Seize patients devant subir une trachéotomie à la suite de la résection d'un cancer oral ont été répartis au hasard en deux groupes : lidocaïne $(n=8)$ et placebo $(n=8)$. Une canule de trachéotomie à ballonnet a été gonflée avec $5 \mathrm{ml}$ de lidocaïne à $4 \%$ ou une solution salée à $0,9 \%$ et de l'air jusqu'à une pression $20 \mathrm{cmH}_{2} \mathrm{O}$, chez les patients des groupes lidocaïne et placebo, respectivement. L'inconfort du tube a été évalué à l'aide de l'échelle visuelle analogique à 0 ; 0,$5 ;$ I; 2 et $4 \mathrm{~h}$ après l'administration de lidocainne ou de solution salée. Aucun analgésique ou sédatif n'a été administré pendant la période d'évaluation.

Résultats : La diffusion de la lidocaïne au travers du ballonnet de la canule de trachéotomie était fonction du temps. Trente et $60 \mathrm{~min}$ après le gonflement du ballonnet, les concentrations de lidocaïne avaient atteint environ 8 et $17 \mu \mathrm{g} \cdot \mathrm{ml}^{-1}$, ce qui représentait 160 et $340 \mu \mathrm{g}$ dans $20 \mathrm{ml}$ d'eau, respectivement. Les valeurs de l'EVA ont diminué de $53,5 \pm 10,6$ à $25,1 \pm 9,8 \mathrm{~mm}(P<0,01)$ 0,5 h après l'administration de lidocaïne, laquelle a été poursuivie jusqu'à la fin de la période d'évaluation. Dans le groupe placebo, l'EVA n'a pas montré de modification. Conclusion : La diffusion de la lidocaïne au travers du ballonnet de la canule de trachéotomie a réduit l'inconfort lié au tube.

From the Departments of Dentistry and Oral Surgery* and Anesthesiology, $\ddagger$ University of Hirosaki School of Medicine, Hirosaki 0368562, Japan, and University Department of Anaesthesia and Pain Management, $†$ Leicester Royal Infirmary, Leicester LE1 5WW, UK. Address correspondence to: Dr. K. Hirota, Department of Anesthesiology, University of Hirosaki School of Medicine, Hirosaki 0368562, Japan. Phone: +81-172-39-5111; Fax: +81-172-39-5112; E-mail: masuika@cc.hirosaki-u.ac.jp Accepted for publication February 2, 2000. 
$\mathrm{F}$

OLLOWING oral cancer resection with radical neck dissection, most patients undergo tracheostomy to avoid postoperative upper airway obstruction from laryngeal edema. These patients suffer from considerable tube discomfort, and sedatives and analgesics are titrated until the tube is tolerated. However, there is a risk of respiratory depression following opioid or minor tranquilizer administration.

Sconzo et al. reported that lidocaine diffuses across the cuff of an endotracheal tube. ${ }^{1}$ This is because the cuff is manufactured from polyvinyl chloride and acts as a semipermeable membrane. In addition, Huang and colleagues have also reported considerable lidocaine diffusion across endotracheal tube cuffs. ${ }^{2}$ In a study by Navarro and Baughman lidocaine from an endotracheal tube cuff was sufficient to produce some local anesthetic action as it was reported that there was a reduction of postoperative sore throat. ${ }^{3}$

In this study, we examined whether lidocaine diffuses across the tracheostomy tube cuff that is routinely used in our hospital, and whether placing lidocaine in the tracheostomy cuff reduced tube discomfort.

\section{Methods}

The protocol was approved by our University Ethics Committee.

\section{In vitro study}

Two tracheostomy tubes ( $\varphi$ con GBII tracheostomy tube, ID $8.0 \mathrm{~mm}$, Fuji Systems, Tokyo) were used in this study. The tube cuff was inflated with $5 \mathrm{ml}$ lidocaine $4 \%$ solution and air at $20 \mathrm{cmH}_{2} \mathrm{O}$, and then placed in $20 \mathrm{ml}$ distilled water at $37^{\circ} \mathrm{C}$. Following vigorous stirring $100 \mu \mathrm{l}$ of this water was sampled immediately and at 1, 2, 4, 8, $24 \mathrm{hr}$ later. The concentration of lidocaine in the samples was measured by high-performance liquid chromatography. The lower detection limits were $0.2 \mu \mathrm{g} \cdot \mathrm{ml}^{-1}$ and the intra-assay coefficient of variation was $5.2 \%$.

\section{Clinical study}

Sixteen adult patients undergoing tracheostomy follow ing oral cancer resection were randomly assigned to two groups: lidocaine group $(\mathrm{n}=8,59.9 \pm 4.5[\mathrm{SE}] \mathrm{yr}$, male $/$ female $=5 / 3)$ and placebo group $(n=8,57.3 \pm 2.7$ $\mathrm{yr}$, male $/$ female $=6 / 2$ ). The following protocol was performed on the 2 nd postoperative day when patients did not require large dose of analgesics and sedatives.

All patients were blinded to study drugs. The tracheostomy tube cuff was inflated with $5 \mathrm{ml}$ lidocaine $4 \%$ or saline $0.9 \%$. The cuff was further inflated with air until cuff pressure reached $20 \mathrm{cmH}_{2} \mathrm{O}$. Tube dis- comfort was evaluated by visual analogue scale (VAS: $0 \mathrm{~mm}=$ no discomfort $; 100 \mathrm{~mm}=$ worst possible dis comfort) before and at $0.5,1,2$ and 4 hr after cuff inflation with lidocaine or saline.

Neither analgesics nor sedatives were given during the evaluation. If patients required analgesics or sedatives during the evaluation, they were excluded from the study.

Statistical analysis was by Repeated Measures ANOVA followed by Fisher PLSD for intra-group comparisons and by unpaired t test for between-group comparisons. A $P<0.05$ was considered significant. All data are expressed as mean \pm SEM.

Results

There was a time dependent increase in the concentration of lidocaine recovered from the incubation medium (Figure 1) indicating that lidocaine diffused across the tracheostomy tube cuff.

In patients who received a tracheostomy tube with a lidocaine containing cuff the VAS decreased from $\mathbf{5 3 . 5}$ \pm 10.6 to $25.1 \pm 9.8 \mathrm{~mm}(P<0.01) 0.5 \mathrm{hr}$ after lidocaine administration and the effect was maintained until the end of the evaluation period. In the placebo (saline) group there was no reduction in VAS (Figure 2).

\section{Discussion}

The present study suggests that considerable amounts of lidocaine diffused across the tracheostomy tube cuff and was sufficient to reduce tracheal tube discomfort. The maximum reduction in discomfort was observed at $30 \mathrm{~min}$ although diffusion continued to increase in a time dependent manner. Thirty and $60 \mathrm{~min}$ after cuff inflation, lidocaine concentrations in the water bath reached approximately 8 and $17 \mu \mathrm{g} \cdot \mathrm{ml}^{-1}$ repre-

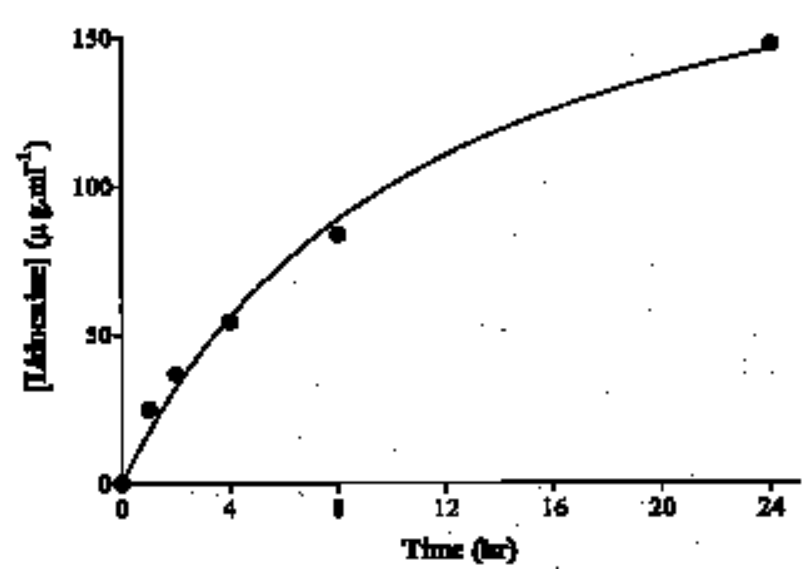

FIGURE 1 Lidocaine diffuses across the tracheostomy tube cuff in a time dependent manner. Data are mean of two experiments. 


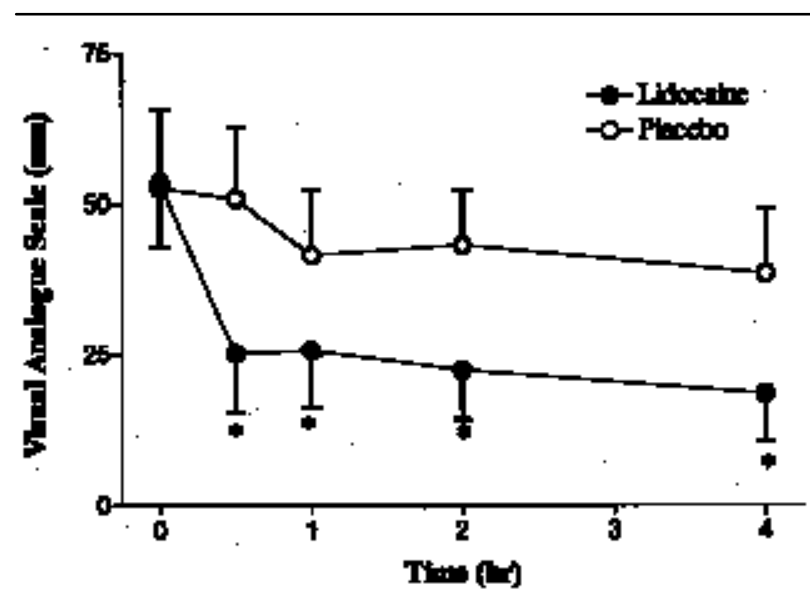

FIGURE 2 Lidocaine from the tracheostomy tube cuff reduces tube discomfort. All data are Mean \pm SEM. ${ }^{*} P<0.01$.

senting 160 and $340 \mu \mathrm{g}$ in $20 \mathrm{ml}$ of water, respectively. These data are in good agreement with those of Sconzo and colleagues of 46 and $360 \mu \mathrm{g} .{ }^{1}$

The amount of lidocaine that diffused through the cuff after 30 min was only $170 \mu \mathrm{g}$ in total. Lidocaine concentrations of $140 \mu \mathrm{M}$ (i.e., equivalent to about $650 \mu \mathrm{g}$ in our $20 \mathrm{ml}$ bath) are required to produce a $50 \%$ reduction in $\mathrm{Na}^{+}$channel activity. ${ }^{4}$ It should be noted that this in vitro data is for homogenous solutions and, in the present study, the concentration of lidocaine where the cuff touches the tracheal surface would have been considerably higher. This small amount of lidocaine is sufficient to produce a demonstrable local anesthetic action, i.e. reduced irritation in the area contacted by the cuff.

In the present study lidocaine produced approximately $50 \%$ reduction in tube discomfort VAS (from $53.5 \pm 10.6(\mathrm{SEM})$ to $25.1 \pm 9.8 \mathrm{~mm}$ ). These data are in good agreement with those of Navarro and Baughman who found that $5.5 \pm 1.4(\mathrm{SD}) \mathrm{ml}$ lidocaine $4 \%$ in the cuff reduced postanesthetic sore throat by about $50 \%$ (severity score: from $18.7 \pm 27$ (SD) to $7.9 \pm 18.1$ and $25.6 \pm 27.5$ to $14.5 \pm 24.8$ one and 24 $\mathrm{hr}$ following anesthesia). ${ }^{2}$

It is possible that increasing the lidocaine concentration in the cuff may reduce discomfort severity by more than $50 \%$. However, as the concentration of lidocaine in the cuff increases, accidental cuff rupture becomes a problem that may result in local anesthetic toxicity. We do not recommend use of higher concentrations.

Whilst tube discomfort is primarily caused by cuff irritation, coughing produced by the irritation increas- es airway secretions, which exacerbates coughing and, hence, produces more discomfort. Intravenous and topical lidocaine are well known to reduce the cough reflex. ${ }^{5-7}$ Therefore, even though lidocaine diffusion does not completely block the direct cuff irritation, it may reduce the cough reflex, secretion and hence further discomfort. In addition, as Mallick and colleagues reported, lidocaine instillation also reduces total propofol and alfentanil requirements for endotracheal tube use in the intensive care unit. ${ }^{8}$ Lidocaine in the tracheal tube cuff might also reduce the need for sedatives and analgesics although this was not assessed in the present study.

In conclusion, the present data suggest that lidocaine diffuses through its cuff of an endotracheal tube and is sufficient to significantly reduce tube discomfort.

\section{Acknowledgment}

We thank Dr. D.G. Lambert (University Department of Anaesthesia and Pain Management, Leicester Royal Infirmary, UK) for his valuable comments.

\section{References}

1 Sconzo JM, Moscicki JC, DiFazio CA. In vitro diffusion of lidocaine across endotracheal tube cuffs. Reg Anesth 1990; 15: 37-40.

2 Huang C-J, Tsai M-C, Chen C-T, Cheng C-R, Wu K$H$, Wei T-T. In vitro diffusion of lidocaine across endotracheal tube cuffs. Can J Anesth 1999; 46: 82-6.

3 Navarro RM, Baughman VL. Lidocaine in the endotracheal tube cuff reduces postoperative sore throat. J Clin Anesth 1997; 9: 394-7.

4 Willow M, Gonoi T, Postma SW, Caterall WA. Inhibition of voltage-sensitive sodium channels by local anesthetics and anticonvulsants. In: Roth SH, Miller KW (Eds.). Molecular and Cellular Mechanisms of Anesthetics. New York: Plenum Press, 1986: 243-58.

5 Yukioka H, Yoshimoto N, Nishimura K, Fujimori $M$. Intravenous lidocaine as a suppressant of coughing during tracheal intubation. Anesth Analg 1985; 64: 1189-92.

6 Nishino T, Hiraga K, Sugimori K Effects of iv lignocaine on airway reflexes elicited by irritation of the tracheal mucosa in humans anaesthetized with enflurane. Br J Anaesth 1990; 64: 682-7.

7 Gonzalez RM, Bjerke RJ, Drobycki T, et al. Prevention of endotracheal tube-induced coughing during emergence from general anesthesia. Anesth Analg 1994; 79: 792-5.

8 Mallick A, Smith SN, Bodenham AR. Local anaesthesia to the airway reduces sedation requirements in patients undergoing artificial ventilation. Br J Anaesth 1996; 77: $731-4$. 